\title{
Heinz Angermeier
}

\section{Reichsreform und Reformation in der deutschen Geschichte*}

Einem Gespräch über säkulare Aspekte in der deutschen Geschichte des 16.Jahrhunderts liegt stillschweigend gewiß der Gedanke zugrunde, man müsse, entgegen einer lange geübten und geradezu selbstverständlich gewordenen Praxis, auch einmal von diesem Jahrhundert reden können, ohne die Reformation in den Mittelpunkt aller Entwicklungen und Ereignisse zu stellen. Doch ist dies nicht als Affront oder gar als Trotzreaktion gedacht, sondern die Frage nach den säkularen Aspekten ergibt sich geradezu natürlich und notwendig aus meinem Bemühen, eine Gesamtdarstellung der Reichsreform vorzulegen, wennschon ich damit nicht verhehle, daß mir die Frage nach den säkularen Aspekten auch über die Reichsreform hinaus nicht nur interessant, sondern sogar als dringend erscheint, gerade auch angesichts der Flut von Luther-Feiern, die für das große Gedenkjahr 1983 bevorsteht.

In der hier zu behandelnden verfassungsgeschichtlichen Version der säkularen Aspekte geht es vor allem um das Verhältnis zwischen Reichsreform und Reformation. Denn bei der im Heiligen Römischen Reich Deutscher Nation gegebenen Orientierung des politischen Lebens auf die religiösen Ziele kann auch die innerste Problematik der Reform dieses Reiches erst dann richtig bestimmt und die Funktion dieser Reform in der deutschen Geschichte erst ganz erkannt werden, wenn man sie nicht einfach als einen Vorgang einer gescheiterten Staatsbildung betrachtet, sondern die spezifisch deutsche Staatsproblematik der frühen Neuzeit gerade aus dem Verhältnis der Reichsreform zur Reformation abliest. Das heißt freilich, daß dieses Verhältnis aus einer mittelalterlichen Sicht bestimmt wird, denn es ist die Mittelalterlichkeit des Reiches, die sich an der Reformation stößt und nicht die Neuzeitlichkeit des Staatsproblems, das ein solches Verhältnis begründen würde. Und das Ausgehen vom Mittelalter eröffnet wohl auch Perspektiven, die der üblicherweise angewandten neuzeitlichen Betrachtungsweise des Verhältnisses von Staat und Reformation verschlossen bleiben. Auch kommt man bei einer Darstellung der Reichsreform um so weniger um dieses Verhältnis zur Reformation herum, als die ausschließliche Okkupation des 16. Jahrhunderts durch die Reformation vor allem daran schuld ist, daß die in der Reichsreform liegende deutsche Staatsproblematik dieser Zeit in der deutschen Geschichtswissenschaft zu kurz gekommen ist.

" Die Form des gesprochenen Vortrags ist hier beibehalten. Bezüglich der Quellenbelege verweise ich auf meinen Aufsatz „Reichsreform und Reformation“, HZ 235/1982. 
Wenn ich darum die beiden Bewegungen der Reichsreform und der Reformation zueinander in Beziehung setze und ihre wechselseitige Abhängigkeit verfolge, so geht es zwar zuerst um die Reichsreform, aber in engem Zusammenhang damit auch um die Frage, ob es der Geschichtswissenschaft nicht gelingen könnte, durch eine Betrachtung aller das 16.Jahrhundert prägenden Gestaltungskräfte möglicherweise zu einer Relativierung der bisher als ausschließlich angesehenen religiösen Bewegung zu gelangen; es geht um eine neue Einstellung zur konfessionellen Spaltung und schließlich um einen Beitrag zur Überwindung des Bruchdenkens in der deutschen Geschichte. Schließlich sind ja die für das 16.Jahrhundert so charakteristischen Neuansätze im Rechtswesen, in der sozialen Entwicklung, im Bereich von Wirtschaft und Finanzen, von Wissenschaft, Literatur und Technik nicht einfach Folgen der Reformation gewesen, sondern sie stehen daneben und haben ihrerseits die Reformation nicht weniger beeinflußt und gefördert, als dies umgekehrt der Fall war. Es geht also um die Möglichkeit, unsere Vorstellung zu revidieren, daß die Reformation die einzige Ursache der tiefen Verānderungen im 16.Jahrhundert gewesen sei, die allein maßgebende Bewegung, welche nach und nach alle anderen Entwicklungsströmungen in sich aufgesogen habe, um am Ende das ganze öffentliche und private Leben in Deutschland und ganz Nordeuropa zu prägen und zu beherrschen. Im engeren Bereich der Geschichtswissenschaft gilt es aber, einerseits endlich wegzukommen von dem im 19. Jahrhundert so wichtig gewesenen Anliegen, die Reformation allein aus der Geschichte zu rechtfertigen, denn in diesem Anliegen liegt auch ein gutes Stück PreuBen-Deutschland von 1871 verborgen, das sich als Reich immer als einen Hort der Reformation betrachtet hat, andererseits aber die bloß wissenschaftspolitische Konstruktion zu durchschauen, mit welcher in Ostdeutschland die Reformationsbewegung in eine frühbürgerliche Revolution umgedeutet und damit die geistesgeschichtliche Verkürzung der Geschichte durch eine sozialgeschichtliche ersetzt wird. Es wäre zu hoffen, daß durch eine umfassendere und objektivere Betrachtung des 16.Jahrhunderts das Bild von der deutschen Geschichte an Weite gewinnt, ohne an Tiefe zu verlieren. Daß diese große Aufgabe nicht allein aus der hier bevorzugten verfassungsgeschichtlichen Fragestellung zu lösen ist, versteht sich wohl von selbst, aber eine Schlüsselfunktion kann man ihr wohl zusprechen.

Man wird das Nahziel, das Verhältnis zwischen Reichsreform und Reformation näher zu bestimmen, wohl am besten dadurch ansteuern, daß man die drei wichtigen Bereiche der kaiserlichen Politik, der religiösen Entwicklung und der Reichstagsergebnisse in der ersten Hälfte des 16.Jahrhunderts auf ihre bisher völlig unterschätzte Relevanz für die Reichsverfassung untersucht, und dazu stelle ich drei konkrete Fragen, nämlich

1. ob man nicht zu einem besseren Bild von Karl V. kommt, wenn man sein Leben und sein politisches Wirken nicht nur in der gewohnten Weise als ein einziges Ringen um die Verteidigung des katholischen Glaubens gegen die neuerstandene evangelische Lehre versteht, sondern wenn man fragt, ob und inwieweit sein politisches Handeln mit der deutschen Verfassungstradition im Einklang steht.

2. muß gefragt werden, ob die religiöse Bewegung des 16. Jahrhunderts tatsächlich so eindeutig und ausschließlich durch die Lehre Luthers und durch konfessionalistische 
Tendenzen bestimmt war, wie dies immer angenommen wird, oder ob nicht in dieser religiösen Bewegung auch reichspolitische und reichsreformerische Anliegen vorhanden waren, welche ihrerseits der Reformation den Weg bahnten und später in Vergessenheit gerieten.

3. erscheint es mir nötig, auch die Geschichte der Reichstage in dieser Zeit ins Auge zu fassen und danach zu fragen, ob diese wirklich so vorrangig oder gar ausschließlich mit der Entwicklung der religiösen Verhältnisse beschäftigt waren, wie es immer als selbstverständlich angenommen wird, oder ob nicht etwa die spätere politische Durchsetzung der konfessionellen Ziele in unbilliger Weise dazu geführt hat, den reichspolitischen und verfassungspolitischen Gehalt dieser Reichstagsverhandlungen zu unterschätzen.

Hinter allen diesen Fragen nach der Verfassungsrelevanz der religiösen Bewegung wird die Möglichkeit sichtbar, den Fortgang der Reichsreform zu erkennen, die freilich in der wissenschaftlichen Literatur immer wieder als gescheitert betrachtet wird. Aber sie wird totgeredet, weil man meines Erachtens in fälschlicher Weise unter Reichsreform immer den Versuch sehen möchte, das mittelalterlich-universalistische Reich in einen modernen Staat auf fiskalischer und militärischer Basis und mit machtpolitischer Ausrichtung umzuwandeln, während die für Deutschland historisch mögliche und auch politisch tatsächlich angestrebte Reichsreform sowohl für den Kaiser, wie auch für die Stände kein anderes Ziel hatte, als das bestehende Reich durch institutionelle Ordnungen und eine verfassungsmäßige Konsolidierung weiterhin zu erhalten und die Rechtsbefugnisse zwischen Kaiser und Ständen in Einklang zu bringen mit den bestehenden Machtverhältnissen. Wenn man aber der Reichsreform eine falsche Reichsvorstellung unterschiebt, nämlich eine staatspolitische, dann ist es freilich leicht, angesichts der Nichtrealisation einer solchen falschen Konzeption nun der Reformation eine staatspolitische Funktion und Legitimation zuzusprechen. Aber man sollte doch endlich wahmehmen wollen, daß kein einziger deutscher Fürst dieser Zeit das Reich zum Staat umwandeln wollte und daß selbst Bertholds von Henneberg gemäßigt zentralistische Vorstellungen nicht weniger als dreimal abgelehnt wurden, und zwar von den Fürsten selbst. So waren auch die Reichsreformbestrebungen unter Maximilian nicht einfach gescheitert, sondern sie waren in den Anfängen stecken geblieben, und mit der neuen machtpolitischen Situation war sowohl für die monarchische, wie auch für die ständische Seite der Abschluß der Reform nicht nur dringender, sondern auch schwieriger geworden. Denn ich betone: Reichsreform ist nicht nur der Kampf der Stānde gegen die Monarchie, sondern das zweiseitige Ringen von Monarchie und Ständen um die Durchsetzung ihrer jeweiligen Reichsvorstellung.

\section{Die kaiserlicbe Reicbsreformpolitik}

Mit der Hinwendung zur ersten Frage, ob Karls V. politisches Wirken in Deutschland sich nur auf die religiösen Angelegenheiten konzentrierte, haben wir es gleich mit der ganzen Problematik des Karls-Bildes in der deutschen Geschichtswissenschaft zu tun. Denn den vier divergierenden Vorstellungen von Karls politischer Orientie- 
rung, nämlich als Religionskämpfer bei Ranke und seinen Nachfolgern bis Lortz und Skalweit, sodann als burgundischer Weltherrscher bei Brandi, ferner als Erneuerer des mittelalterlichen Universalkaisertums bei Rassow und schließlich wohl primär als Machtpolitiker bei Lutz, ist doch dies eine gemeinsam, daß Karl V. in Deutschland ein Fremder gewesen sei und daß er folglich auch eine den deutschen Traditionen und Verhältnissen entsprechende Herrschaftsform und Verfassungspolitik nicht entwickelt habe. Es illustriert dieses Bild in charakteristischer Weise, daß der Reichstagsaktenband zum ersten wichtigen Reichstag Karls V. in Worms 1521 für die Luther-Frage 34 Stücke bringt, zu den Verfassungsproblemen 27 Stücke und zu den außenpolitischen Angelegenheiten 12 Stücke, wobei aber der Kampf um Mailand als auslösendes Ereignis keine Beachtung fand und auch Burgund, England, Ungarn und Dänemark nicht besonders vorkommen. Für den Verfassungshistoriker Fritz Hartung waren eigentlich nur die letzten neun Jahre Karls von 1546-1555 interessant, während eine Verfassungsgeschichte zum 16. Jahrhundert bisher überhaupt nicht geschrieben wurde.

Es leidet aber keinen Zweifel, daß die Vorstellung von einem durchgehenden Vorrang der Religionsfragen bei Karl V. nicht den historischen Gegebenheiten entspricht, sondern von einer konfessionspolitischen Interessenlage bestimmt ist, und speziell für den Reichstag von 1521 kann ich aus Kenntnis der Aktenlage und aus meiner Erfahrung bei der Reichstagsaktenedition nur sagen, daß das von der Wissenschaft überlieferte Bild das Verhältnis von Aktenlage und historischer Wertung geradezu auf den Kopf stellt. Die geringe Berücksichtigung bei der Aktenedition darf nicht darüber hinwegtäuschen, daß 1521 neben dem Italienkrieg für den Kaiser die traditionsmäßige Aufrichtung des Reichslandfriedens, sodann seine erfolgreichen Bemühungen um seine gesteigerte Gerichtsgewalt und schließlich die Ausgestaltung des Reichsregiments im kaiserlichen Sinn im Vordergrund standen. Mit allen diesen Regelungen, bei denen sich Karl übrigens ständig auf seinen Vorgänger und Großvater Maximilian berief, lag auch ein verfassungspolitisches Programm vor, das in hohem Maße der Reichstradition verbunden und dazu bestimmt war, die Reichsreform in einer monarchischen Tendenz zu Ende zu führen. Es unterstreicht diesen traditionalistischen Charakter der Regierungsführung Karls V. in Deutschland, daß er hier von Anfang an bis zuletzt am Lehensstaat festhielt, daß ferner alle verfassungsrelevanten Ordnungen gemeinsam mit den Reichsständen auf Reichstagen verabschiedet wurden wie eh und je. Schließlich aber ist hervorzuheben, daß schon der junge Karl V. die Reichsreform gerade nicht durch monarchische Finanz-, Verwaltungs- und Militärreformen verfolgte, welche den neuzeitlich-absolutistischen Machtstaat zum Ziele hatten, sondern daß die Intensivierung und Verbesserung der Reichsverfassung durch ihn gerade auf dem Weg der traditionellen Gesetzgebung, der Verbesserung von Friedensrecht, Strafrecht, Prozeßrecht, Konzentration der Gerichtsordnung und Exekution erfolgte. In allen diesen verfassungspolitischen Maßnahmen kann man keine Absichten zur Verānderung entdecken, sondern die Reform hatte durchaus einen konsolidierenden Charakter.

Diese traditionalistische Verfassungspolitik Karls V. könnte nun in ihrer positiven Entwicklung sehr wohl verfolgt werden im Bereich der Gerichtsbarkeit, wo er bis 1548 die Kammergerichtsbesetzung und die Ächtungsgewalt voll zurückgewonnen hatte; sie könnte im Exekutionswesen aufgezeigt werden, wo der Kaiser aus alten habsburgi- 
schen Erfahrungen unter bewußter Übergehung von Kreisorganisationen bis zuletzt seine Bundesprojekte pflegte; sie könnte aufgezeigt werden in der Praxis des Regierungsapparates und schließlich in der Reichsgesetzgebung im Erbrecht, Strafrecht, im Polizei- und Münzwesen. Schließlich könnte diese traditionalistische Verfassungspolitik sehr eindrucksvoll herausgearbeitet werden bei ihrer Negation eines rein ständischen Reichsregiments, eines modernen Steuerwesens und einer verfügbaren Kriegsorganisation, was ich alles hier ausdrücklich anspreche, aber im Interesse meines eigentlichen Themas Reichsreform und Reformation nicht weiter ausführe.

Die entscheidende Frage für unser Thema lautet aber, ob diese monarchische Reichsreformpolitik Karls V. nicht doch zwangsweise in eine andere, eben religionspolitische Bahn umgeleitet wurde, als dem Kaiser mit der 1530 in Augsburg präsentierten Confessio Augustana die Fülle und Universalität der kaiserlichen Gewalt aus einer neuen, religiösen Argumentation heraus bestritten wurde. Und diese Frage nach einer möglichen Sprengung der traditionellen Verfassungspolitik wird noch unterstrichen durch die Tatsache, daß auf demselben Reichstag 1530 Karl die Königswahl Ferdinands durchsetzen konnte, womit das Reichsregiment als Promotor der ständischen Reichsreformideen ein Ende fand und in der Verfassungsordnung die Durchsetzung des monarchischen Gedankens erneut bevorzustehen schien. Tatsächlich hat auch der Rechtshistoriker Rudolf Smend aus beiden Ereignissen - dem Ende des Reichsregiments und der Königswahl - den Schluß gezogen, man müsse „im Augsburger Abschied in gewissem Sinne den Abschluß der Reformperiode sehen“, denn ,anstelle des Gegensatzes von König und Ständen auf dem Gebiet der Reichsverfassung war der der Altgläubigen und der Protestanten getreten, der seitdem die Geschichte des Reichs und seiner Verfassung beherrscht" habe.

Aber dagegen möchte ich eine ganz andere Frage setzen, nämlich ob nicht das Reichsreform-Engagement Karls V. durch die Augsburger Ereignisse eher erweitert als vermindert wurde und ob nicht die von 1530-1555 geführte Politik des Kaisers als eine nunmehr fast schon bedenkenlose Einbeziehung der religiösen Frage in seine Bemühungen um Einheit und Ordnung des Reiches unter der kaiserlichen Gewalt zu verstehen ist. Denn es war doch ein Faktum der Reichsverfassung, daß 1530 in Augsburg zum ersten Mal durch einen Reichstag eine Glaubensdefinition vorgenommen und für reichsrechtlich verbindlich angesetzt wurde, daß ferner nun nicht nur die Verānderung im Kirchenbesitz, sondern auch die Abweichungen vom Glauben der Kammergerichtsbarkeit unterstellt wurden, daß weiterhin das Kammergericht nun kompetenzmäßig ebenso wie auch in seiner Kapazität für die Erhaltung der religiösen Einheit ausgerüstet wurde. Tatsächlich war durch die Protestanten auf der einen Seite und andererseits mit dem kaiserlichen Entschluß, alle Religionsabweichungen als Bruch des Reichsfriedens gerichtlich zu verfolgen, die Reichsreform in ein neues Stadium eingetreten, sie wurde neben den Fragen der Reichsregierung, des öffentlichen Friedens, der Gesetzgebung nun um die Dimension der religiösen Ordnung erweitert und sie ist zugleich mit der Frage der Kompetenz des Kaisers in die letzten Tiefen der Reichsverfassung vorgestoßen.

Ein anderes Problem ist es allerdings, ob der Reichsreform durch diese Erweiterung um das religiöse Problem auch ein Dienst erwiesen wurde, ob es eine förderliche, eine 
berechtigte und eine sinnvolle Erweiterung war, oder ob Karl V. nicht 1530 die Bereinigung der religiösen Differenzen besser zunächst der sich im Hintergrund haltenden Kirche überlassen hätte. Denn neben den Möglichkeiten der Aussöhnung oder der Unterwerfung durch den Kaiser hätte es gerade angesichts der päpstlichen Haltung auch 1530 noch eine Bewahrung der kaiserlichen Religionsverantwortung, vor allem aber der vollständigen Friedensgewalt gegeben, wenn der Kaiser angesichts des kirchlichen Schweigens eine vorbehaltliche Säkularisierung erwogen hätte. Mit der Anwendung der verfassungsrechtlichen und vollen Gerichtsgewalt auf den Bereich des religiösen Bekenntnisses wurde aber notwendig der Ausgang der Reichsreform mit Erfolg oder Mißerfolg der kaiserlichen Religionsbemühungen verknüpft.

$\mathrm{Da}$ dieser Ausgang für den Kaiser negativ verlief, wissen wir. Aber es ist nötig, hier hinzuzufügen, daß die diplomatischen und militärischen Niederlagen Karls V. nur noch bestätigten, was eigentlich seit 1548 schon religionspolitisch entschieden war, und zwar gerade deshalb, weil sich Katholiken wie auch Protestanten, wenn auch jeweils aus anderen Motiven, der kaiserlichen Religion des Interims widersetzten und gerade jene Einheit und Ordnung nicht mehr wünschten, die Karl sich zum Ziel gesetzt hatte. Seine künstlichen und rationalistischen Einigungsversuche, die sich z. B. darin zeigen, daß er das Fasten deshalb empfahl, weil sonst das Fleisch für die Ernährung der Bevölkerung nicht mehr ausreichen könnte, verfingen bei den religiösen Kräften nicht mehr. Im Interim von 1548 zeigt sich, daß Karls Reichsreform in eine Hybris hineingeraten war, daß sie eben mit ihrer Glaubensdefinition aus politischen Gründen sich in Bereiche hineinwagte, für welche die kaiserliche Autorität a priori nicht mehr ausreichte. Hier war eine Totalmonarchie postuliert, die schon im Begriff war, die auf dem Dualismus von geistlicher und weltlicher Gewalt aufgebaute Universalität des Mittelalters zu verlassen. Denken wir daran, daß sich das Abendland im politischen Kosmos der alten Welt gerade dadurch heraushebt, daß hier geistliche und weltliche Gewalt nicht in einer Hand lagen, wie im türkischen Sultanat, und auch nicht in der Dominanz der weltlichen über die geistliche Gewalt, wie in Konstantinopel, sondern in einer nie fixierten und auch nicht fixierbaren Balance sich befanden. Karls Reichsreformpläne waren also nicht an der Reformation Luthers gescheitert, sondern sie zerbrachen an der eigenen kaiserlichen, also religiös bestimmten Reichsreformkonzeption, die eigentlich latent schon in der Konzilspolitik Kaiser Sigmunds vorlag, die unter Karl V. und den Bedingungen des 16. Jahrhunderts aber ihren hybriden Kern vollends offenbarte. Verfassungsmäßig zeigt sich also, daß die monarchische Gewalt, die in Deutschland unter Wenzel ihre natürliche Basis im Königtum verloren hatte, seit Sigmund eine Reichsreformpolitik aus betont kaiserlich-universalistischen Ansprüchen entfaltete, bis sie in den religiösen Wirren unter Karl V. bemerken mußte, daß ihr die dafür vermeintlich zu Gebote stehende religiöse Legitimation letztlich nicht zukam oder jedenfalls nicht ausreichte.

Von diesem Ausgang abgesehen ist hier abschließend festzuhalten, daß es für Karl V. sehr wohl eine spezifisch deutsche Reichsreformpolitik gegeben hat, durchgehend vom ersten Tag seiner Regierung bis zu seiner Abdankung. Sie ging aus von der Vorstellung einer Konsolidierung und Verbesserung der inneren Reichsordnung durch die Stärkung der monarchischen Gewalt, blieb aber dabei verfassungsmäßig den 
Grundlagen des mittelalterlichen Lehensstaates verhaftet und war im wesentlichen darauf ausgerichtet, auch die volle landrechtliche Gewalt wieder dem Kaisertum zurückzuerobern. Die Reformation hat wesentlich dazu beigetragen, daß im Zuge dieser Reichsreformbemühungen auch die seit dem Mittelalter schon dem Kaisertum zugeschriebene religiöse Verantwortung stärker zum Ausdruck kam und sogar für die verfassungsrechtliche Stellung des Kaisers herangezogen wurde, aber es muß mit Entschiedenheit daran festgehalten werden, daß diese Vorstellungen von den religiösen Grundlagen der kaiserlichen Gewalt auch schon im 15. Jahrhundert den kaiserlichen Reichsreformbestrebungen innewohnten. Hybride Züge waren dieser kaiserlichen Politik also von Anfang an inhärent und die Verhältnisse des 16. Jahrhunderts haben nur ein übriges dazugetan, um sie nun auch voll zur Wirkung kommen zu lassen. Es war deshalb nur konsequent, daß mit dem Scheitern dieser Religionspolitik auch die speziellen Verfassungsbestrebungen der kaiserlichen Reichsreformpolitik nicht zum Ziel gelangten. Religionsfriede und Exekutionsordnung sind die beiden Gewichte, die auf dem Augsburger Reichstag 1555 die Balance des Reichsfriedens hergestellt haben. So ist es für das Verständnis der deutschen Staatsentwicklung und der ganzen deutschen Staatsproblematik in der frühen Neuzeit von großer Wichtigkeit zu sehen, daß eine Reichsreform im monarchischen Sinn nicht deswegen gescheitert ist, weil die Monarchie als solche das Reich verändern oder verstaatlichen wollte, sondern gerade deshalb, weil das Kaisertum sich in seinem mittelalterlich-religiösen Selbstverständnis auch im 16.Jahrhundert treu geblieben ist und sich gerade damit in der religiösen Krise nicht zu behaupten vermochte.

\section{Die Reichsreform in der religiösen Bewegung}

Vielleicht erweckt mein Versuch, die Politik Karls V. von einer neuen Warte aus zu sehen, den Verdacht, es handle sich dabei nur um eine neue Verpackung für eine alte Sache, und deshalb wende ich mich jetzt meiner zweiten Frage zu, die sich damit beschäftigt, ob es nicht außerhalb und unterhalb dieser höchsten politischen Sphäre in der reformatorischen Bewegung selbst eine wechselseitige Beziehung zwischen reichsreformerischen und religiösen Impulsen gab, welche uns bestätigen kann, daß diese Zeit nicht einfach und allein aus der Reformation verstanden werden kann. Natürlich ergibt sich diese Frage vor allem für die Wirren der zwanziger Jahre, bei deren Studium man sich ja nicht des Eindrucks erwehren kann, daß eigentlich nur ganz wenige Menschen wie Philipp von Hessen, Luther oder eben Karl V. wirklich wußten, was sie wollten. Aber auch in den vierziger Jahren gibt es noch Zeugnisse, wie das große Memorandum des Naumburger Reformbischofs Julius Pflug über den Reichsfrieden oder die Säkularisationspläne am kurbrandenburgischen Hof, aus denen durchaus ein Wissen von der Parallelität von Reichsreform und Reformation zutage tritt. Ich greife hier aus der Frühzeit der Reformation nur die wichtigsten Beispiele heraus und verweise zuerst auf den jungen Luther selbst.

In seiner Schrift „An den christlichen Adel deutscher Nation“ aus dem Jahr 1520 wird der Gedanke einer Zusammengehörigkeit von Reichsreform und Kirchenreform 
ganz unmißverständlich ausgesprochen, da Luther darin bereits die Verantwortung der weltlichen Gewalt für die Kirchenreform postuliert und fragt, „was zu solchen greulichen wesens (in der Kirche) wohl geschehen müßte und sollte von weltlicher Gewalt oder gemeinem Konzilium“. Die Schrift war Karl V. gewidmet, und auch für die Berufung des Konzils hat sich Luther an den Kaiser gewandt. Aber darüber hinaus wird man Luther wohl nicht Unrecht tun, wenn man sagt, daß er zu diesem Zeitpunkt noch meinte, die Herstellung der Ordnung im geistlichen und weltlichen Bereich sei ein einziger Akt, und noch überzeugt war, mit der vom Kaiser hergestellten Reform der Kirche sei auch das Reich bereits reformiert. Denn die eigentlichen Probleme der Reichsreform hat Luther nach dem Zeugnis dieser Schrift jedenfalls nicht erkannt, sondern vielmehr gedacht, das Reich sei nur wegen der Übergriffe des Papsttums ruiniert und reformbedürftig, so daß mit der Aufhebung der geistlichen Gerichtsbarkeit, mit der Zurückweisung des römischen Fiskalismus, mit der Abstellung der durch die Stellenbesetzungspolitik ausgeübten Kirchenherrschaft, ferner mit der Aufhebung aller kaiserlichen Verpflichtungen, Huldigungen und Treueide gegenüber dem Papst und schließlich mit der Beseitigung der päpstlichen Verfügungsgewalt über die Reichslehen, das Königreich Neapel und den Kirchenstaat auch die Integrität des Reiches wieder voll restituiert werden könne. Die Kirchenreform mündet nach diesem frühen Werk Luthers direkt und automatisch in eine Reichsreform zugunsten eines starken Kaisertums, mit der auch die gottgewollte Ordnung auf Erden wiederhergestellt sein würde. Erst die Absage Karls V. an Luther auf dem Wormser Reichstag 1521 hat dann dazu geführt, daß sich drei Jahre später in seiner Schrift „Von weltlicher Obrigkeit" der Gedanke der totalen Trennung von weltlicher Gewalt und religiösem Gebot herauskristallisierte und mit dieser Zwei-Reiche-Lehre jede weltliche Reformbewegung und politische Aktion ihre Bedeutung für die Gestaltung des religiösen Lebens verloren hat.

1520 aber ist Luther auch noch Patriot, und dieser dem Reich geltende Patriotismus war wohl nicht die geringste Ursache dafür, daß die Reformation in Deutschland so starken Anklang gefunden hat. Und insofern das Reich für ihn der wichtigste Repräsentant der Gottesherrschaft auf Erden war, ist Luther 1520 auch noch Traditionalist gewesen, wenn auch diese Tradition durch ihre antirömische Tendenz bereits leer geworden war, weil das Reich ja für Luther keine eigenen religiösen Funktionen wie die der Mission oder der Glaubensverteidigung hatte, und damit die ideelle Basis der mittelalterlichen Reichsidee verschwunden war. Indem er die päpstliche Translatio imperii weder anerkannte noch durch eine andere Legitimation ersetzte, war es für ihn „ohne Zweifel, daß das erste römische Reich, davon die Propheten 4, Mose und Daniel verkündet haben, längst zerstört ist und ein Ende hat“. Das Reich ist für ihn ein Reich der Deutschen, es ruht allein auf der Geschichte und dem weiter nicht ableitbaren Willen Gottes, „der solch Reich uns durch listige Tyrannen hat zugeworfen und zu regieren bevolhen “. Wir können diese Vermischung und Verwischung von Reichsreformdenken und religiöser Reformation und ihre Steigerung zu Patriotismus und leerem Traditionalismus in der Geisteswelt des 16. Jahrhunderts noch häufig antreffen, ich erinnere an Hans Eberlin von Günzburg, an Ulrich von Hutten oder an den Bauernführer Friedrich Weigandt, aber hier mag Luthers Zeugnis genügen für die 
Feststellung, daß am Beginn der Reformation die religiöse Bewegung ohne die politische Reform nicht denkbar gewesen ist.

Ein weiterer wichtiger Beleg für die wechselseitige Wirkung von Reichsreform und Reformation ist sodann die mächtige Bewegung um die Gravamina Nationis Germaniae, die Beschwerden der deutschen Nation. Sie geht ja in ihren Ursprüngen schon zurück auf die Vorstadien zum deutschen Konkordat von 1448, wurde unter Kaiser Maximilian verschiedentlich wieder aufgegriffen und hat dann auf dem Wormser Reichstag 1521 - also lange bevor es einen expliziten Protestantismus und Konfessionalismus gab - gerade von seiten der katholischen weltlichen Fürsten, besonders durch Herzog Georg von Sachsen, eine vehemente Neubelebung gefunden. Denn jetzt war sie ebenso als ein Mittel zur Eindämmung der Luther-Bewegung gedacht, wie auch als ein Weg zur Bereinigung des Verhältnisses zwischen den geistlichen und den weltlichen Reichsfürsten. Insofern ist diese Gravamina-Bewegung auf der einen Seite die erste halb politische und halb religiöse Demonstration, die den verfassungsrechtlichen Bestrebungen der Stände eine politische Erweiterung und auch einen neuen Impuls hinzufügte; andererseits ist die jetzt von den Reichsständen aufgenommene Gravamina-Bewegung von 1521 ein wichtiges Zeugnis für die deutsche nationale Version der ganzen Kirchenreformbewegung überhaupt, die zwar durch Luther neue Aktualität erhielt, aber deswegen doch mit Luther selbst nichts $\mathrm{zu}$ tun hatte. Nun ist zwar dieser große Versuch, die lutherische Reformation zu bremsen und eine neue Reichsordnung auf Kosten der Reichskirche zustande zu bringen, auf der Strecke geblieben, weil sich die politisch potenten Faktoren davon nichts versprachen: die katholischen geistlichen Fürsten waren an einer solchen Verfolgung ihrer Mißbräuche nicht interessiert, die protestantischen Fürsten haben sich von der Bewegung je länger desto mehr zurückgezogen, weil sie dadurch beim Aufbau und Ausbau ihrer territorialen Landeskirche gestört worden wären, die großen weltlichen katholischen Fürsten, wie die Herzöge von Bayern, kümmerten sich weniger um die Reichskirche, als um eine ihrem Einfluß offene Staatskirche, und schließlich versagte sich auch der Kaiser einer solchen nationalen Lösung der Kirchenreform, denn er erstrebte eine durch ein Konzil bewirkte universale Kirchenreform und ihm lag natürlich auch nichts an der kirchenrechtlichen Stärkung der Reichsstände. Zwar hat sich Karl V. auf dem Augsburger Reichstag von 1530 um einen Ausgleich zwischen den gegenseitigen Beschwerden der geistlichen und weltlichen Fürsten bemüht, aber den Rat des Kardinallegaten, der Kaiser möge als Oberhaupt des Reiches beim Papst auf die Beseitigung der Beschwerden dringen, hat er doch nicht verfolgt, sondern eben die ganze Kirchenreform auf das Generalkonzil abgestellt. So ist angesichts des Desinteresses von Kaiser und Fürsten die Gravamina-Bewegung der zwanziger Jahre versandet, sie hat weder für die Kirchenreform noch für die Reichsreform irgendwelche Ergebnisse oder auch nur Fortschritte gebracht. Aber eine historische Betrachtung darf doch nicht einfach an den Möglichkeiten vorbeigehen, die sich gerade in dieser Gravamina-Bewegung sowohl für die Kirchenreformbewegung wie auch für die Reichsreform boten. In der Nichtausschöpfung dieser Möglichkeit bzw. in der Nichterledigung der religiösen Frage im Jahr 1521 durch Karl V. wird man doch ein ernstliches Versäumnis sehen müssen, vielleicht sein größtes. 
Damit komme ich für die Frage nach dem Zusammenhang von Reichsreform und Reformation innerhalb des religiösen Bereiches $\mathrm{zu}$ dem vielleicht wichtigsten Kapitel, nämlich welche Vorstellungen Karl V. von einer kirchlichen Reform in Deutschland hatte, die in den Rahmen der Reichsreform eingeordnet werden kann. Die aktiven Bemühungen Karls V. haben sich gewiß auf eine universale und konziliare Kirchenreform konzentriert, wie sie Hubert Jedin zuletzt umfassend darstellte. Aber aus den von Georg Pfeilschifter publizierten „Acta Reformationis Ecclesiae Catholicae" gewinnen wir doch einen Blick auf die passive Schlichterrolle des Kaisers als Reichsoberhaupt über die Differenzen zwischen den Bischöfen und den weltlichen katholischen Fürsten, und von diesem Wirken Karls läßt sich deutlich ablesen, wie er sich neben seiner entschiedenen antiprotestantischen Haltung eine Reform in der katholischen Kirche in Deutschland vorstellte, die seinem Anliegen der Restitution einer aus Kirche und Reich bestehenden Christenheit unter kaiserlicher Herrschaft entsprach.

Die Differenzen waren schon bald nach dem Auftreten Luthers entstanden, ihre Bereinigung hatte zunächst durchaus den Zweck, den Angriffen gegen die Kirche durch eine Selbstreform den Boden zu entziehen, aber sie waren rasch ausgeartet in einen heftigen Streit zwischen den geistlichen und den weltlichen katholischen Kräften, hinter dem die ursprünglich gemeinsame Frontstellung gegen die Reformation Luthers völlig in Vergessenheit geriet. Denn die weltlichen Fürsten betrachteten eine solche Reform als eine Gelegenheit, nicht nur die Mißbräuche, sondern auch die Privilegien und die Vorrangstellung der Kirche abzustellen und selbst in die herrschaftlichen Rechte der Kirche einzutreten und dadurch Kontrolle, Einfluß und Befugnisse zu erlangen, durch welche eine staatskirchliche Entwicklung eingeleitet werden konnte. Gegen solche Tendenzen jedoch wandten sich die Bischöfe mit aller Entschiedenheit. Der Hildesheimer Domherr Valentin von Tetleben klagte die weltlichen Fürsten an, sie seien mit dem Kirchengut viel schlimmer umgegangen als die Lutheraner, und der Erzbischof von Salzburg hat die Kommissarien der katholischen Herzöge von Bayern als ein Raubgesindel hungriger Wölfe bezeichnet. Die geistlichen Fürsten forderten demgemäß, daß die ihnen von den weltlichen Fürsten entwendeten Befugnisse zurückgestellt würden, ja sie erklärten, daß jede Reform ihrem Wesen nach überhaupt Wiederherstellung der alten reichskirchlichen Position sei.

In diesem großen innerkatholischen Streit kam nun aber dem Kaiser auf dem Reichstag zu Augsburg 1530 das Schiedsgericht über die wechselseitigen Klagen zu, und es ist klar, daß seine Stellungnahme auch eine Entscheidung der obersten Reichsgewalt über den Weg der Kirchenreform innerhalb der katholischen Kirche war. Dabei hat sich aber Karl V. ganz eindeutig auf die Seite der Bischöfe gestellt, sich für die Erhaltung der alten Reichskirche und ihrer überkommenen Rechte ausgesprochen und sein Votum nicht für die Veränderung zugunsten einer Staatskirche, sondern zugunsten der Erneuerung der alten Reichskirche abgegeben. In seinem streng rechtlichen Schiedsspruch von Augsburg, der als kaiserliche Konstitution die Rechtslage der deutschen Kirche klären sollte, hat Karl V. zwar einen reformerischen Standpunkt eingenommen, er hat die Erneuerung der Kirchenzucht in den Vordergrund gestellt und die mit den Rechten der Kirche und des Klerus verbundenen Pflichten stark betont, aber er hat doch die überkommenen Ansprüche der Kirche in ihren Besitzun- 
gen, bei der Besteuerung, Zehnterhebung, Ausübung der Gerichtsbarkeit, Freiheit der Stellenbesetzung, Verfügung über das Kirchengut, Unterordnung der kirchlichen Hintersassen und anderes mehr, vollauf bestätigt. Den territorialfürstlichen Instanzen wurde lediglich ein Subsidiaritätscharakter zugesprochen, falls die kirchlichen Instanzen ihren Aufgaben nicht nachkämen. So wie Karl V. einmal zu Philipp von Hessen gesagt hat: „reformieren heißt nit einen neuen Glauben annehmen“, so kam auch sein Spruch in Augsburg einer vollen Restitution der alten Kirche gleich, und damit wird deutlich, daß das Reich auch jetzt weder territoriale Staatskirchen zulassen wollte noch eine eigene, quasi staatskirchliche Kompetenz erstrebte, sondern unter der Bedingung der Bereinigung in der alten Reichskirche an deren ständischer Macht und kirchlicher Selbständigkeit festhielt. Die vom Kaiser ausgeübte Schiedsgerichtsbarkeit deutet zwar eine Kontrollgewalt über die Einhaltung dieser Reformmaßnahmen an und unterstreicht damit Einfluß und Sorgegewalt des Kaisers in der deutschen Reichskirche, aber deren Erhaltung war auch ein Votum gegen die Staatskirche, gegen die Fürstengewalt in der Kirche, ein Votum gegen die Stärkung des Fürstentums auf Kosten der Kirche. Insofern war aber auch schon Karls V. Konzept der Erhaltung einer in sich gefestigten Reichskirche ein wichtiger Beitrag zu der von ihm angestrebten Konsolidierung des Reiches, und zwar im Sinn einer Stärkung der Reichsgewalt durch diese restituierte reichsstāndische Kirche.

\section{Die Reichsreform und die Reichstage}

Man sieht also, es besteht zur Behutsamkeit bei der Beurteilung der Reformation aller Anlaß, was ja auch die vielen Konkordanzversuche des 16. Jahrhunderts und die von Erich Hassinger herausgestellten Absetzbewegungen von der protestantischen Sache zur Genüge beweisen. Ich möchte mich hier jedoch nicht tiefer in die geistesgeschichtlichen Entwicklungen verlieren, sondern eher in der politischen Geschichte nochmals die Kontrolle gewinnen, die als Zeitgenosse schon der kursāchsische Rat Hans von der Planitz vermißte, als er an seinen Kurfürsten schrieb: „thett woll als nott ein reformacion in der juristerei, als in der theologei durch den Luther beschehen ist“. Wir werfen dazu unserer dritten Frage entsprechend noch einen Blick auf die Reichstage dieser Zeit, die ja in den historischen Darstellungen meistens bis zur völligen Verkennung und Verzeichnung für die Reformation in Beschlag genommen werden. Es geht aber doch eigentlich nicht an, daß man für Worms 1521 nur vom Lutherverhör und vom Wormser Edikt spricht, für Nürnberg 1524 nur vom nichtzustandegekommenen Nationalkonzil, für Speyer 1526 nur von der ersten Religionskonzession an die Protestanten, für 1529 nur von deren Rücknahme und der Protestation der evangelischen Stände, für Augsburg 1530 nur von der Behauptung der Confessio Augustana, für Regensburg 1532 und 1541 sowie für Speyer 1544 nur von den nächsten Religionskonzessionen, für Augsburg 1548 nur vom gescheiterten Interim bis hin zum Augsburger Reichstag 1555, bei dem es selbstverständlich geworden ist, ihn für den Religionsfrieden zu okkupieren, während die verfassungsrechtlichen Regelungen dort höchstens noch als dessen Nebenprodukt erwähnt werden. 
Nun leidet es gewiß keinen Zweifel, daß mit dem Auftreten Martin Luthers auf dem Wormser Reichstag 1521 auch in der Reichstagsgeschichte eine neue Epoche beginnt. Denn im Mittelalter dienten solche Reichsversammlungen in der Regel der Vorbereitung von Reichskriegen oder Italienzügen, seit Kaiser Sigmunds Zeiten wurden dann auch Beratungen zur Verbesserung der Reichsverfassung unter die Reichstagsthemen aufgenommen, jetzt aber ging es um die Erhaltung der Glaubenseinheit und des religiösen Friedens. Somit finden die Reichstage seit 1521 auch stärker das gesellschaftliche Interesse, dort erhält die Reichsverfassung ihre verbindlichen Formen und Formulierungen, sie gewinnen Bedeutung für die Ordnung des kirchlichen Lebens, erstrecken ihre Kompetenz auf das Verhältnis des Reiches zum Papsttum und gewinnen schließlich Entscheidungsgewalt darüber, ob der Kaiser noch Schützer des Glaubens und der Einheit in der Christenheit bleiben kann oder ob er nur als Repräsentant und Mediator in den politischen Angelegenheiten des Reiches fungieren soll. Es war also 1521 nicht nur eine neue Materie zu den Reichstagsgeschäften hinzugekommen, sondern im Gegensatz zu den bisher mehr occasionellen Reichstagsanlässen und -entscheidungen haben durch die Vertiefung ins Religiöse alle Reichstagsberatungen nunmehr einen grundsätzlichen Charakter erhalten. Zwar sind die großen außenpolitischen Fragen und Kriegszwänge der Hintergrund der Reichstage geblieben, aber die Hilfsforderungen dafür auf den Reichstagen waren für Kaiser und Reich jetzt verbunden mit Religionskonzessionen, welche gleichzeitig Kaisertum und Reichsidee in ihrem alten Selbstverständnis in Frage stellten. Ebenso haben zwar die Kriege gegen die Türken, gegen Frankreich, Geldern oder um Ungarn auch jetzt keine Umgestaltung der Wehrverfassung und nicht die Wende zum Finanzstaat mit sich gebracht, aber in Verbindung mit den religiösen Fragen haben sie auf den Reichstagen für die Stände die Möglichkeit eröffnet, die Reichsverfassung in ihrem Sinn auszulegen, die kaiserliche Gerichtsbarkeit lahm zu legen, die Gültigkeit von bloßen Mehrheitsbeschlüssen abzulehnen und Gegenbündnisse im Reich einzuführen. Ohne daß man deshalb schon die ständisch-verfassungsmäßige und die religiöse Opposition gegen den Kaiser in einen Topf werfen dürfte, wie es Ranke getan hat, hat sich doch der Reichstag durch diese Weiterungen im 16.Jahrhundert zu einer eigenständigen Form der Reichsrepräsentation entwickelt und damit auch eine bestimmte politische Macht gewonnen, ja man könnte sagen, er hat von 1521-1555 jene Kompetenzen an sich gezogen, welche zuerst 1495 und dann 1521 einem Reichsregiment zugedacht waren. Eine Folge dieser Entwicklung ist aber zweifellos gewesen, daß der Reichstag auch in zunehmendem Maße zum Forum nicht nur für die Religionsentscheidungen, sondern auch für die Weiterführung der Reichsreform geworden ist.

So war schon die Errichtung von Reichsregiment und Reichskammergericht 1521 ein Werk des Reichstags, und Konrad Repgen hat gezeigt, wie auch das Lutherverhör in Worms nicht nur als eine reformatorische Demonstration gesehen werden darf, sondern darüber hinaus eine gravierende Wende im Verfassungsverständnis von Reich und Reichstag darstellte. Der Kampf um das Reichsregiment, dessen einzelne Stadien ich hier übergehe, war sodann für alle Reichstage bis zu dessen Ende durch Ferdinands Königswahl 1530 eine zentrale Verfassungsangelegenheit, die völlig zu Unrecht in den Hintergrund geschoben wurde. Denn hier ging es mit dem Bemühen um die 
Unterhaltung der Reichsinstitutionen entweder durch Steuern oder Kirchenabgaben oder Reichszoll oder Matrikularbeiträge der Stände nicht nur um die Finanzverfassung, sondern angesichts der Auseinandersetzungen um die Kompetenz des Regiments auch um hoheitliche, jurisdiktionelle und exekutorische Probleme, die über Form und Fortgang der Reichsreform überhaupt bestimmten. An wichtigen Verfassungsentscheidungen der nächsten Reichstage erwähne ich hier nur die Aburteilung des Regiments, die Beschränkung seiner Befugnisse und die Aufhebung seiner jurisdiktionellen Gewalt in Nürnberg 1524, sodann die Übergabe der Landfriedensgewalt gegenüber allen Empörungen nach dem Bauernkrieg an die Reichsstände in Speyer 1526, sodann auf dem nächsten Reichstag zu Speyer 1529 die Ausschaltung der Reichsstädte durch die Fürsten, die Bildung von Visitationskommissionen des Reichstags über Regiment und Kammergericht und schließlich auf dem Augsburger Reichstag 1530 vor allem die gegen die Vorschriften der Goldenen Bulle vollzogene Königswahl Ferdinands und die Verabschiedung der Reichsgesetze zum Erbrecht, zum Polizeiwesen und zum Strafrecht. Alle diese Entscheidungen brachten auch eine Intensivierung der Reichstagsgeschäfte und -entscheidungen. In dieser Intensivierung kommt zum Ausdruck, daß die Stände ihre Reichsreformvorstellungen gegen diejenigen der Monarchie jetzt nicht mehr durch besondere Institutionen verfolgten, sondern eben durch die repräsentativere und potentere Form des Reichstags selbst. Man könnte geradezu sagen, daß sich durch diese Konzentration der Stände auf dem Reichstag schon in den Jahren 1521-1531 die neuen Vorstellungen der Stände vom Reich als einem Verband herauskristallisieren, der eigenständig über seine politische Existenz entscheidet, ohne noch eine herrschaftliche Gewalt zu akzeptieren.

In den Wirren der vierziger und fünfziger Jahre mit ihren großen Entscheidungen von Crepy, Mühlberg und Passau haben die Reichstage an Bedeutung noch zugenommen und demgemäß auch die Wechselwirkung von reichsreformerischen und reformatorischen Anliegen noch stärker zur Geltung kommen lassen. Zunächst haben schon die erweiterten Religionskonzessionen Karls V. auf den Reichstagen zu Regensburg 1541 und zu Speyer 1544 der reformatorischen Bewegung einen starken Schub gegeben, ja mit der Zulassung von Protestanten zum Reichskammergericht schien ihr schon eine verfassungsmäßige Position gesichert. Aber protestantische Reformation und kaiserliche Reichsreform hielten sich in Speyer 1544 die Waage, die Hoffnungen für die Sicherung der Reformation mußten bezahlt werden mit großen Fortschritten für die kaiserliche Verfassungspolitik, bei der Kammergerichtsbesetzung, einer stark rationalisierten Steuerordnung und einer Fortentwicklung der Kreisordnung im Reich. Schon konnte Karl V. sagen, sein Kammergericht sei nicht nur Rechtsinstanz, sondern es sei überhaupt an die Stelle des Reichsregiments getreten. Und noch mehr Aussichten boten sich dem Kaiser für den nächsten Reichstag, nachdem er 1546 die Protestanten militärisch besiegt hatte, denn jetzt glaubte er mit seinem Interim die Reformation überwinden und mit einem gefügigen Reichsbund jenes Exekutionsinstrument gewinnen zu können, mit dem er die Feinde seiner Religionsordnung in Schach halten wollte. Emphatisch sagte er zum venezianischen Gesandten: „Jetzt wird meine Liga vorankommen und keinen Schwierigkeiten mehr begegnen“.

Notwendig hätte ein solcher Reichsbund und der Sieg der kaiserlichen Reichsre- 
formvorstellungen nicht nur die Korrespondenz zwischen Reichsreform und Reformation aufgehoben, indem er die Reformation beseitigte, sondern er hātte wohl auch künftigen Reichstagen nur mehr wenig Raum und Bedeutung gelassen. Darum war entscheidend, daß der Augsburger Reichstag von 1548 nicht zum kaiserlichen Reichsbund führte und zwar unter der Führung des Erzbischofs von Mainz, wie Horst Rabe zeigte. Im gemeinsamen Widerstand der katholischen und protestantischen Fürsten gegen den Abschluß der Reichsreform im kaiserlichen Sinn zeigt sich, daß die Stände seit dem Ende ihres Reichsregiments niemals die eigenen Reformvorstellungen aufgegeben hatten und daß sie nicht „nur für sich kämpften“, wie Fritz Hartung meinte.

So war es denn nochmals ein Augsburger Reichstag, der 1555 nach den kriegerischen Entwicklungen der vorangegangenen Jahre allen seit Karls Regierungsbeginn entstandenen Problemen und Entwicklungen ein Ende setzte, indem er den Landfrieden dadurch sicherte, daß er den Religionsfrieden im konfessionellen Sinn akzeptierte. Der Wunsch der Stände, eine kaiserliche Verfassungshandhabung durch eine ständische Verfassungsübereinkunft zu ersetzen, war stärker als die Übereinstimmung der Katholiken mit den Habsburgern oder der Lutheraner mit den Calvinisten. So war es nach den Forschungen von Rolf Decot auch 1554/55 wieder, wie schon 1547/48, der Erzbischof von Mainz, der als Führer der Reichsstände die endgültige Anerkennung der Reformation in Kauf nahm, um dafür die Reichsreform im Sinn der Stände zum Abschluß bringen zu können.

Wie die reformerischen Bestrebungen in steigendem Maße zum Bestandteil der Reichstagsgeschichte wurden, so ist bis zum letzten Reichstag Karls V. die Anerkennung der Reformation der Preis für die Durchsetzung einer ständischen Reichsreform geblieben. Nicht die Kriege, nicht die Bündnisse und nicht die Diplomatie haben die Konfrontation in den konfessionellen Fragen und den Kampf um die Reichsverfassung zum Abschluß gebracht, sondern der politische Kompromiß auf den Reichstagen. Der Augsburger Reichsabschied dokumentiert mit Religionsfrieden und Exekutionsordnung nochmals, daß auch die Geschichte der Reichstage, ebenso wie die Betrachtung der kaiserlichen Politik und der reformatorischen Entwicklung nicht nur verstanden werden darf im Zeichen der Reformation. Die Abdankung Karls V. war nicht nur ein Sieg der Reformation, sondern auch ein Sieg der ständischen über die monarchischen Reichsreformbestrebungen und sie kennzeichnet in einem viel weiteren Sinn den Wandel, der in Deutschland in ideeller, politischer, verfassungsmäßiger und konfessioneller Hinsicht im 16.Jahrhundert zum Abschluß gekommen war. Die auf den Reichstagen zu Ende geführte Reichsreform hat das Kaisertum zwar als Symbol für die Einheit des Reiches behalten, aber ihm auch die im Reichstag garantierte Libertät der Reichsstände aufgezwungen und dem Reich anders als den Staaten der Neuzeit die Verfassung eines Friedensverbandes gegeben, welcher im Innern bestimmt wurde durch den Ausgleich der ständischen Interessen und nach außen durch die gemeinsame Verpflichtung für den Schutz und die politische Existenz dieses Reichs. Man wird darum auch die Bedeutung der Reformation für die Entstehung und den Geist des modernen Staates nicht schmälern, wenn man feststellt, daß in Deutschland die politische und verfassungsmäßige Entscheidung gegen den Staat ein Werk der Reichsreform gewesen ist. Gerade die Betrachtung der Reichstage konnte hier ei- 
nen wissenschaftsgeschichtlich sehr bemerkenswerten Befund erbringen, der sich konkret vor allem an der Entwicklung der Reichstagsaktenedition ablesen läßt. Hatte doch Ranke 1836 bei der Sichtung des Reichstagsaktenbestandes im Frankfurter Stadtarchiv gemeint, die Edition der für die Zeit von 1376-1519 vorliegenden Reichstagsmaterialien in „zwei nicht allzu weitläufig gedruckten Quartbänden“ bewerkstelligen zu können, um dann gleich an sein zentrales Anliegen einer Erschließung der Reformationsgeschichte im Licht der Reichstage herantreten zu können. Heute aber, wo 20 Bände Reichstagsakten zur Zeit vor der Reformation und 8 Bände für die ersten Jahre der Reformationszeit vorliegen, ergibt das Studium der auf den Reichstagsakten basierenden deutschen Verfassungsgeschichte das neue und unerwartete Bild, daß sich Umfang und Bedeutung der Reformation durch den Gang der Verfassungsgeschichte betrāchtlich relativieren und die Wirkung der Reformation nicht so hoch veranschlagt werden darf, als ob alle anderen Entwicklungen davon beherrscht worden wären.

\section{Scbluß}

Damit komme ich zum Schluß meiner Ausführungen, die der Frage galten, ob die Reformation tatsächlich jenes alles beherrschende Ereignis der deutschen Geschichte des 16. Jahrhunderts war, als welches es in der Geschichtsschreibung erscheint, oder ob es daneben andere Bewegungen gibt, die aus irgendwelchen Gründen zu Unrecht verdrängt und in ihrer Bedeutung verkannt wurden, die aber bei einer historisch angemessenen Würdigung nicht minder eine konstitutive Bedeutung in der Entwicklung beanspruchen dürfen. Diese Frage habe ich verfolgt, indem ich das Phänomen der verfassungspolitischen Reichsreform in der kaiserlichen Politik, sodann innerhalb der religiösen Strömungen und schließlich in der Entwicklung der Reichstage herausstellte. Ich hoffe, daß es mir gelungen ist aufzuzeigen, wie es sehr wohl neben der Reformation eine eigenständige Reichsreformbewegung gibt, ja, wie es eigentlich nicht möglich ist, die Reformation richtig zu verstehen, wenn man sie nicht in dieser Wechselwirkung und das heißt natürlich in dieser Beschränkung erfaßt. Denn nicht sie aus dem Bewußtsein zu verdrängen, sondern sie in der richtigen Relation zu sehen, war mein Ziel. Wenn die Wissenschaft diesen Anstoß aufnehmen und fortführen würde, könnte sie wohl auch die Vorstellung überwinden, daß mit der Reformation im 16. Jahrhundert ein unheilbarer Bruch in die deutsche Geschichte und in die deutsche Geisteswelt eingetreten ist. Darüber hinaus könnte sie erweisen, daß die deutsche Staatsentwicklung eben unter Bedingungen stand, die mit denen der übrigen Staaten Europas in keiner Weise zu vergleichen ist und gerade deshalb nicht als das krampfhafte Bestreben betrachtet werden darf, ein Staat zu werden, sondern als das alte und seine Traditionen bewahrende Reich eine Sonderstellung in der europäischen Staatsproblematik beanspruchen muß. Ein richtiges Verständnis der immer ein wenig im Schatten der Wissenschaft gebliebenen Reichsreform könnte jedenfalls ein Weg sein, um durch diese Richtigstellung der Proportionen im 16.Jahrhundert auch für das 20. Jahrhundert Impulse zu gewinnen. Aber wenn die Wissenschaft dadurch fortschreitet, daß sie rationaler wird, so heißt dies im Bereich der Geschichte nicht unbe- 
dingt, daß sie auch an Optimismus zunimmt. Denn die Erschließung der Vergangenheit durch mehr Rationalität ist nur die eine Seite ihres Ertrags, die Einsicht in die für das Leben entscheidende Irrationalität der Gegenwart die andere Folge ihres Tuns.

\section{Diskussion zum Referat Angermeier}

Lutz: Zunächst herzlichen Dank für dieses thesen-, anregungs- und perspektivenreiche Referat. Es ist so anregend, daß es keine Schwierigkeit wäre, in gleicher Länge und Ausführlichkeit aus dem Stand heraus zu antworten, um nicht zu sagen zu erwidern. Ich wähle ein paar Punkte aus, wo, wie ich glaube, nicht nur meine persönliche Interpretation, sondern der Forschungsstand zu einer anderen Formulierung von Fragen und teils auch zu anderen Antworten uns veranlassen kann. Als erstes: das ganze Problem, also Karl V. und Reichsreform. Ich persönlich versuche seit 30 Jahren mich mit diesen Dingen herumzuschlagen, habe aber meine Auffassung von Karl V. eigentlich in keiner der vier skizzierten Konzeptionen wiedergefunden; denn „Weltreich aus burgundischem Geist", das ist der alte Brandi, über den wir nun durch eine intensive Kritik Gott sei Dank schon hinaus sind. Ich glaube, daß es hier entscheidend ist, die Vorfrage zu stellen, die eigentlich im Referat nicht so vorgekommen ist; dieser Vorfrage habe ich ja vor einem Jahr mein Kolloquium hier gewidmet, nämlich: welchen Stellenwert hat in dem politischen Gesamtsystem des Kaisers das römisch-deutsche Reich mit seinen Verfassungsfragen? Und ich glaube, wenn man die Ergebnisse dieses Symposiums noch einmal rekapituliert, kann man eine ziemlich eindeutige Antwort auf diese Vorfrage geben. Das Reich hat insgesamt nicht die führende, sondern eine sekundäre, zeitweilig sehr untergeordnete Rolle im politischen Gesamtsystem des Kaisers gespielt. Das Reich hat immer wieder eine große Formalbedeutung gehabt, weil es Karl V. die Kaiserkrone gegeben hat. Aber diese Kaiserkrone war ja für Karl V. nicht die Aufforderung, das Reich als solches zu reformieren, sondern eben eine universale Konzeption durchzusetzen. Das Reich gerät dadurch in eine Nebenrolle, bekommt also eine funktionale Rolle. Wenn man diese Vorfrage in dieser Perspektive sieht, verändert sich sozusagen alles weitere, was wir an argumentativem Material haben. Ich würde so weit gehen zu sagen, selbst in den acht Jahren 1544-52, in denen der Kaiser sich ganz überwiegend im Reich aufhielt, werden seine Versuche zur Reichsreform (natürlich immer mit Anknüpfung an traditionalistische Motive) immer wieder durchkreuzt durch die Bedürfnisse und Ziele seiner außerdeutschen Politik und durch die Ubberordnung der außerdeutschen Prioritäten seiner Politik und seiner Herrschaftssicherung über die innerdeutschen Bedürfnisse der Reichsreform. Das hat zerstörerisch gewirkt. Nicht dies allein, sondern auch die Versuche der dynastischen Zukunftssicherung des Weltreiches. Das zeigt das Beispiel der spanischen Sukzession. Und hier hört es also ganz auf, daß Reichsreform, Kaiser, Stände sozusagen im Modell einer innerdeutschen Existenz stehen können. Wenn der Kaiser alles daran setzt, seinen Sohn, der König von Spanien wird, zum Kaiser im Reich zu machen, dann 
kommt dadurch ein Verfremdungselement in alle Reichsreform, in alle reichspolitischen Aktionen des Kaisers, das man gar nicht ernst genug nehmen kann.

Ein anderes Beispiel: die Niederlande. Die eindeutige Konsequenz, eindeutig zumindest seit 1530, geht dahin, daß die Niederlande vom Kaiser ausgegliedert werden sollen aus dem Reichsverband, ausgegliedert, wie Reichsitalien ausgegliedert werden soll aus den Reichsbezügen zugunsten der direkten Bindungen an Spanien. Das muß doch alles in seiner vollen Härte und seiner unmittelbaren, alle organischen innerdeutschen Reichsreformansätze überschneidenden und korrumpierenden Wirkung gesehen werden.

Zweite Bemerkung: die Reichskirche. Das scheint mir fast noch wichtiger. Ich finde es außerordentlich dankenswert, mit welchem Nachdruck dieses Problem der Reichskirche angesprochen wurde. Ich würde die Bedeutung ebenso sehen, würde aber die Perspektive wesentlich anders ansetzen. Voran steht die Frage, wieweit diese Reichskirche im Sinn des mittelalterlichen Dualismus weltlicher-geistlicher Gewalt in der Gestaltung der öffentlichen Dinge über das 15./16.Jahrhundert hinaus überhaupt noch reformierbar war. Wieweit gab es da überhaupt noch evolutionäre, reformistische Lösungen? Das ist eine Frage, die man sich stellen muß. An diese petitio principii wurden wir zwar herangeführt, aber beantwortet wurde sie nicht, jedenfalls ist es mir nicht deutlich geworden. Ich habe also aufgrund des empirischen Materials außerordentliche Zweifel, ob diese alte Reichskirche noch irgendwie reformierbar war; denn was dann später nach den Krisen 1648 herausgekommen ist, war eine „Halbruine“, die aber nun ganz anders abgestützt. war durch den tridentinischen Reformkatholizismus. Luther, der von einer verinnerlichten Glaubensvorstellung ausgeht, der sich hinsichtlich des Priesterideals und des Bischofsideals nicht ganz fern von den damaligen katholischen Reformvorstellungen befindet, hofft anfangs wohl noch, es könnte diese Reichskirche sich - wenigstens teilweise - in der Richtung seiner Reformideen wandeln. Aber das geht spätestens seit 1531 nicht mehr. Da wird der Konflikt Luthers und der Reformation mit der anscheinend unreformierbaren deutschen Reichskirche einer der Angelpunkte der ganzen Entwicklung.

Damit wäre ich nun bei meinem dritten Punkt in aller Kürze. Dieser Konflikt stört nun und hindert von innen her jedes weitere Zusammenarbeiten von geistlichen und weltlichen Reichsfürsten im Sinne einer Reichsreform; das zeigt sich vor allem auf den Reichstagen. Sicher, auch ich halte es für außerordentlich wichtig und möchte das unterstreichen, wir müssen die Verfassungsarbeit der Reichstage sehr viel ernster nehmen als früher. Ich kann aber nicht sehen, daß 1555, also mit dem Augsburger Reichstag, die ständische Reformbewegung zu einem wirklich konstruktiven Ergebnis gekommen ist. Ich greife einen Gesichtspunkt heraus. Der zentrale Punkt, nämlich das Problem der Reichskirche, bleibt in dem Augsburger Religionsfrieden genau der strittige Punkt. Der Paragraph des geistlichen Vorbehalts, über den kein Konsens der Stände erreicht wurde, sondern wo Ferdinand aus kaiserlicher Vollmacht zugunsten der Katholiken entschied, wurde in seiner reichsrechtlichen Verbindlichkeit dann von den Protestanten bestritten. So wird also durch den geistlichen Vorbehalt genau das ungelöste zentrale Problem der Reichsverfassung bezeichnet: wie soll es mit den geistlichen Reichsfürsten weitergehen. 
Angermeier: Ich erwidere dazu zunächst, daß meine Fragestellung unter Absehung von der Reichs- und der Außenpolitik nur dahinging: Was hat Karl tatsächlich an Verfassungspolitik geleistet? Hier glaube ich, ist in der bisherigen Geschichtsschreibung seine Bedeutung und auch sein Engagement für die Erhaltung, für die Konsolidierung der Reichsverfassung unterschätzt worden. Ob sie untergeordnet oder nebengeordnet war, das stelle ich hier praktisch außer Diskussion. Meine Frage lautete nicht, ob und wie Karl seine Verfassungspolitik eingruppiert und selbst beurteilt hat, sondern was er für eine Verfassungspolitik geführt hat und diese Frage ist ja vernachlässigt worden. Demgemäß hat auch die Frage nach der Reichsreform unter Karl V. niemand ernstlich behandelt. Hätte man es aber getan, so könnte man sicher nicht davon sprechen, das Reich habe für ihn eine Formalbedeutung gehabt, es habe nur eine Nebenrolle gespielt. Und das Dilemma bei der Beurteilung Karls liegt ja zudem darin, daß man seine deutsche Politik entweder nur durch die nationale Brille gesehen hat oder sie eben in seiner Universalpolitik verschwinden ließ, aber sie nie unter den sicheren Kriterien der Verfassungsfragen verfolgte. Auch der Successionsplan Karls ist kein Gegenbeweis, weil ja auch ein Philipp notwendigerweise Reichsreform hătte betreiben müssen, wenn er sich in Deutschland eine monarchische Position aufbauen wollte. Und was die Niederlande betrifft, so sind sie durch die Heirat von 1475 tatsächlich ein so besonderes Problem, daß sie mit der Reform der Reichsverfassung in Deutschland zunächst nichts zu tun hatten.

Zweitens Reichskirche. War sie reformierbar. Hier muß ich ganz kurz 1530 ansprechen. Pfeilschifter hat dargelegt, daß 1530 eine kaiserliche Konstitution erstellt wurde, die tatsächlich zur Kirchenreform in Deutschland geführt hätte. Die Konstitution ist nur deshalb geplatzt, weil der Kurfürst von der Pfalz sich dagegen gewehrt hat. Ein auBerordentlich wichtiges Ereignis des Augsburger Reichstags ist deshalb eigentlich überhaupt nicht ins Bewußtsein der Wissenschaft gedrungen, eben Karls Reformbemühungen um die deutsche Reichskirche, und zwar deshalb, weil dieses Bemühen dank der pfälzischen Intervention nicht zum Tragen gekommen ist. Man müßte dann die kaiserlichen Bemühungen zur Kirchenreform über den Kardinallegaten beim Papst noch heranziehen und sieht auch dort, daß zwar die Reform nicht begonnen wurde, daß aber die Reformierbarkeit damit nicht bestritten ist. Karl V. hat zwar sicherlich nichts getan, um die Gravamina aufzuheben, aber daß die Kirche nicht reformierbar war, ist ebenso eine unerwiesene These, wie man sagen könnte sie war reformierbar.

Dritter Punkt: 1555 wäre für die Verfassung, für den Abschluß der Reichsverfassung schließlich und endlich kein Ergebnis gewesen. Ja, da kann ich nur sagen, aber es gibt doch ein völlig neues Reichskammergericht, es gibt auch eine völlig neue Reichskreisordnung, mit der das Kaisertum nach einem 150-jährigen Ringen um die Exekution im Reich, um die tatsächliche Polizeigewalt, um die tatsächliche Militärgewalt und schließlich um die Reichstagskompetenz die Segel gestrichen hat. Speziell seit Augsburg 1555 ist das Kaisertum aus der Regierungsgewalt ausgeschieden. 1555 scheint mir eben verfassungsmäßig tatsächlich ein Wendepunkt zu sein, vor dem es verfassungsmäßige, kaiserliche Machtmittel im Reich gegeben hat, während es sie hernach nicht mehr gab. Das ist die Wende, die verfassungspolitische Wende von 1555, mit der die Verfassungsgestaltung im Sinn der Stände abgeschlossen wurde. 
Lutz: Wende ja, aber nicht ein Ergebnis im Sinne des Sieges einer ständischen Reichsreform als konsolidierter Plattform.

Angermeier: Aber ich habe doch gesagt, das Reich ist ein Reichsfriedensverband geworden mit der Organisation des inneren Friedens auf der ständischen Basis und mit der gemeinsamen Organisation der Reichsverteidigung nach außen. Das Reich ist von einem undefinierbaren Konglomerat vor 1555 verfassungsmäßig zu einem Verband geworden, der als Monarchie schlechthin nicht mehr anzusprechen war und keine zentralistische Möglichkeit mehr gehabt hat, während er in der Kreisverfassung den ständischen Tendenzen eine institutionelle Absicherung gab.

Lutz: Darf ich noch einen Satz dazu sagen: ich verweise auf die Ungelöstheit des Zentralproblems der Reichskirche; das bedeutet eine langsame, aber anscheinend unaufhaltsame Erosion. Gegen dieses ungelöste Problem kommen die übrigen Errungenschaften von 1555 nicht auf, wie dann der Weg ins 17.Jahrhundert zeigt.

Neubaus: Ich möchte an das Ergebnis Ihrer Ausführungen anschließen, Herr Angermeier, in dem Sie formulieren, Reichstage hätten die Reichsreform im ständischen Sinne zu Ende geführt, und ich möchte an das aknüpfen, was Herr Lutz am Schluß gesagt hat. Wenn Sie die Reichstage bis 1555 meinen, Herr Angermeier, dann würde ich das für zu eng gefaßt halten. Reichsreform geht darüber hinaus. Wenn man aber die zweite Hälfte des 16. Jahrhunderts einbezieht - und ich verstehe das Thema des Kolloquiums unter Einbeziehung des gesamten 16. Jahrhunderts - und damit auch die Reichstage dieser Zeit, dann trifft - glaube ich - das nicht mehr zu, was wohl im großen und ganzen für die erste Hälfte des 16. Jahrhunderts gilt: daß nämlich Reichsreform im Sinne traditioneller Gesetzgebung auf den Reichstagen stattgefunden hat. Ich denke, wir sind uns darüber einig, daß von systemrationalen Überlegungen in dieser Zeit nicht gesprochen werden kann, Reichsreform folglich nicht auf sie zurückzuführen ist. Für die zweite Hälfte des 16.Jahrhunderts ist nun doch gerade festzustellen, daß der Reichstag zeitweilig sehr an Bedeutung verloren hat, daß es neue Formen reichsständischer Beratung gab, die bis hin zu Versuchen der Substitution des Reichstages führten. Ich möchte daran erinnern, daß in Folge des Ausbaus der Reichskreisverfassung seit den 1530er Jahren mit den Reichskreistagen eine neue Versammlungsform entstand. Indem ständische Deputationen aus allen Reichskreisen hier zusammen berieten, haben die Reichsstände ein ganz neues Verfassungsinstrument in die Hand bekommen. Und die ordentlichen Reichsdeputationstage, die 1555 für etwas ganz anderes eingesetzt worden waren, bekamen nach 1564 auch eine - ganz vorsichtig formuliert - den Reichstag in Frage stellende Bedeutung, den Reichstag unterlaufende Funktion. Reichskreistag und Reichsdeputationstag sind einmal dadurch gekennzeichnet, daß sie sich - zum Teil - unabhängig vom Reichstag ohne Einsetzungsbeschluß eines Reichstages selbständig konstituierten und auch Reichsrecht schufen. Drei Beispiele wären hier zu erwähnen: Einmal der Reichskreistag in Erfurt 1567. Hier wurde eine Türkensteuer beschlossen, was bis dahin - und Winfried Schulze hat darauf ja in seinem Buch „Reich und Türkengefahr im späten 16. Jahrhundert“ auch 
hingewiesen - allein Angelegenheit des Reichstags gewesen war. Zum zweiten wurde 1577 auf dem Frankfurter Reichsdeputationstag die Reichspolizeiordnung verabschiedet, die bis zum Ende des Alten Reiches in Kraft war. Und drittens wurden auf den Reichsdeputationstagen an der Wende vom 16. und 17. Jahrhundert die ganz entscheidenden Regelungen für die Reform des Reichskammergerichts beraten und beschlossen, die dann in den Beschluß von 1613 einflossen. Auch wenn sie 1613 nicht reichsrechtlich verabschiedet worden sind - weil der Reichstag scheiterte -, so sind sie doch gleichfalls bis zum Ende des Reiches wirksam gewesen. Ich würde also die Begrenzung, wie Sie sie vorgenommen haben, doch weiter ziehen, und ich würde dann so weit gehen und sagen: Reichsreform endet nicht 1555 und findet nicht nur auf Reichstagen statt, sondern reicht bis in die Epoche des Dreißigjährigen Krieges hinein. Dies ist zurückzuführen auf die bis dahin zu beobachtende Offenheit, Unausgetragenheit und Beweglichkeit des Reiches, die dann ab 1648 abgelöst wurden durch Stagnation und Beharren.

Woblfeil: Die Ausgangsfrage von Herrn Angermeier ist durch die Begriffe 'Reichsreform' und 'Reformation' geprägt. Daß über den Inhalt von 'Reichsreform' und 'Reichsreformbewegung' ein weitgehend übereinstimmendes Verständnis besteht, sei postuliert. Im Interesse der Diskussion erbitte ich jedoch eine kurze Beschreibung Ihres Reformationsbegriffes.

Außerdem noch eine knappe Bemerkung: In einem Satz wurde auf die marxistischleninistische Geschichtswissenschaft eingegangen und deren These als sozialgeschichtliche Verkürzung bestimmt. Dieser Eindruck kann sich ergeben, jedoch sollte nicht übersehen werden, daß sich die These von einer deutschen frühbürgerlichen Revolution und die aus ihr resultierende Beurteilung der Reichsreformbewegung aus einem völlig anderen geschichtstheoretischen Ansatz mit anderen Kategorien ableitet als dem historischen Verständnis, das hinter der kritischen Wertung von Herrn Angermeier steht. Von daher erscheint das Urteil einer 'Verkürzung' problematisch.

Angermeier: Zunächst Herr Neuhaus, wir sind uns natürlich ganz einig, daß man die Verfassungsinstitutionen vor 1555 und die Reformpolitik nicht auf den Reichstag reduzieren kann. Ich habe den Reichstag nur als Beispiel herausgerissen. Ihre zweite Frage ist problematischer. Die Reichsreform, sagen Sie, geht nach 1555 weiter. Wenn man darin die weiter geführten Versuche des Kaisertums sieht, schließlich doch noch zur Macht zu kommen und zwar auf dem Wege über die Reichskriegsverfassung, dann ist dem durchaus zuzustimmen. Wenn man für die inneren Verhältnisse auf die Beziehung des Kaisers zu den Territorien und zur Reichsfriedensordnung sieht, dann scheint mir nach 1555 eine solche Reformbewegung nicht mehr vorzuliegen, sondern im Grunde genommen waren es nur noch Ausformungen z. B. in der Visitationsordnung, auch in den Reichsdeputationstagen, Ausformungen dessen, was 1555 vorgelegen hat. In der Kriegsverfassung ist ein tatsächliches Reformstreben eine offene Frage, weil ja hier das kaiserliche Generalat, die Fragen der Truppenwerbung und des Aufgebots, Fragen der Rüstung und Depots ständig im Fluß geblieben sind, und in diesem Bezug könnte man auch eine Fortführung von Reformtendenzen nach 1555 wissenschaftlich versuchen. 
Herr Wohlfeil, was ist mein Reformationsbegriff. Ich würde glauben, daß man die Reformation, so wie sie vor uns liegt, außer in der Theologie, sicherlich in sehr vielen Bereichen, vor allem natürlich in der Staatsauffassung, in der Wirtschaftsgesinnung, in der Einschätzung des Individuums usw. sehen muß. Hierauf kann man eigentlich in einem Satz gar keine Antwort geben. Für die Reichspolitik liegt aber das Problem der Reformation doch in der Spaltung der einen Christenheit in zwei Konfessionen.

Becker: Sie haben in berechtigter Weise Kritik geübt an dem Dualismusschema, das Fritz Hartung aufgestellt hat - Stände gegen Monarchie - und darauf hingewiesen, daß die Stände eine gewisse transzendierende Vorstellung hatten. Es ging nicht nur um ihre Interessen, es ging ihnen auch, wie dem Kaiser, um das Reich. Klaus Schlaich hat neuerdings wieder auf die Bedeutung der Verfahrensfragen auf dem Reichstag, die maioritas, die Parität, die amicabilis compositio hingewiesen. Meine Frage ist: Sind diese Rechtsfiguren im Anschluß an die Reformation, aufgrund einer religionsmäßigen Vertiefung der Problematik, entwickelt worden oder hat man sich ihrer nur bedient? Wie ist das Verhältnis von Tradition und Neubeginn hinsichtlich dieser substantiellen Begriffe?

Angermeier: Man wird wohl sagen müssen, daß diese ganze Entwicklung, die instrumentale Entwicklung der Reichstagsverfassung, schon seit dem Reichstag von 1486 durchaus im Gang ist, daß Ausschußbildungen, Visitationskommissionen und diese Dinge vorgebildet sind. Und ich würde deshalb betonen, daß gerade die Entwicklung und Ausformung der Reichstagsverfassung nicht ein Ergebnis der Reformationsgeschichte ist, sondern eine Fortsetzung der Reichsreform, die auf jeden Fall so oder so auch stattgefunden hätte. Der Reichstag war im Kommen, das ist seit 1486 unwiderrufbar. Die besonderen Formen der Reformationszeit haben das gefördert, aber nicht mehr im Grunde genommen verändert.

Kobler: Herr Angermeier, Sie wissen, daß ich stets eine Aufwertung der ,säkularen“ Phänomene des 16.Jahrhunderts vertreten habe. Wenn man sich allerdings mit Karl V. beschäftigt, so steht man vor der Analyse einer komplexen Sachlage. Herr Angermeier, Sie versuchen die kaiserliche Religionspolitik und auch ihren Reformcharakter mit der Verfassungsreformpolitik des Kaisers zu integrieren. Meines Erachtens gab es für Karl V. überhaupt keine Alternative, also ohne Religionsfrage die Verfassungsfragen voranzutreiben. Sie haben von Luther gesprochen und in den zwanziger Jahren die traditionalistischen Züge in Luthers Entwicklung hervorgehoben. Dies ändert sich aber unter dem Druck der sächsischen Juristen und der Widerstandsdebatte. Der Augsburger Reichstag 1530 dürfte auch in dieser Hinsicht eine Zäsur markieren.

Angermeier: Ich habe gesagt, verfassungsmäßig zeigt sich, daß die monarchische Gewalt in Deutschland unter Wenzel ihre natürliche Basis im Königtum verloren hat. Das ist eine sehr wichtige Sache, denn so lange das Kaisertum auf einem funktionierenden Königtum ruhte, war auch seine kaiserliche Autorität unumstritten, also bis zum Ende Karls IV. Die religiöse Gewalt hat eigentlich nicht zur Debatte gestanden. Als aber die königliche Basis verloren war, ist bei Sigmund zu sehen, daß er nicht mehr als deutscher König regiert und agiert, sondern das Kaisertum ganz in den Vor- 
dergrund geschoben hat. Er hat vor allem Konzilspolitk gemacht, damit seine kaiserliche Autorität ausgespielt. Und ich habe dann von der Hybris gesprochen und gesagt, im Grunde genommen war seit Sigmund eigentlich diese Reichsreform schon auf die Vorstellung von einem Kaisertum ausgerichtet, das es im Abendland nie gegeben hat, nämlich ein Kaisertum, das gleichzeitig weltliche und religiöse Gewalt hatte. Unter Sigmund ist das eigentlich nicht ins Bewußtsein getreten, weil das Konzil noch eine innerkatholische Angelegenheit war, aber die Reformation hat dann gerade diesen religiösen Anspruch im Kaisertum herausgefordert und das Kaisertum zu einem letzten Bekenntnis gezwungen. Karl ist dazu gelangt, eine kaiserliche Religion definieren zu müssen. Hier lag auch die Hybris, hier hat er die Grenzen seines Kaisertums von Anfang an überschätzt und hier lag auch die Ursache dafür, daß eine monarchische Reichsreform im Sinn eines solchen Kaisertums wohl auf keinen Fall zum Zuge kommen konnte.

Kobler: Luther ist natürlich Traditionalist, aber das ändert sich. Es ist ja überhaupt ziemlich unmöglich, die verfassungspolitischen Vorstellungen Luthers zu systematisieren. Vieles läßt sich von Luthers Theologie ableiten, und auch sie ist situations- und zeitbedingt. Nach 1530 hält Luther den Kaiser nicht mehr für jene Institution, welche die Religionsfrage einer Lösung zuführen kann.

Angermeier: Im Zuge meiner Fragestellung habe ich herausgestellt, daß es mir darum geht, ob es innerhalb der religiösen Bewegung selbst auch Momente gibt, bei denen nicht mehr rein religiöse Zielsetzungen vorliegen, sondern von vornherein auch Reichsreform. Wir sind uns sicherlich darin einig, daß sich das mit der Schrift "Von weltlicher Obrigkeit" ändert. Hier hat Luther eine ganz neue Position eingenommen, aber am Anfang der Reformation bis 1524 nimmt er eine undifferenzierte Stellung zum Problem der Reichsreform ein, eine undifferenzierte Stellung, die dazu geführt hat, daß er mißverstanden wurde und daß er im Grunde genommen als ein verkappter Reichsreformist betrachtet wurde. Nach 1524 ist die Sache klar.

Reinbard: Gestatten Sie mir eine Bemerkung und eine Frage. Zunächst eine Bemerkung. Ich finde es sehr wichtig in Ihrem Referat, daß Sie wieder einmal die Frage nach dem Verhältnis von Religion und Politik gestellt haben. Das wurde von Herrn Wohlfeil aufgegriffen, der Sie nach einer Reformationsdefinition gefragt hat. Man könnte sagen, Reformation ist im 16.Jahrhundert nichts anderes als Politik. Herr Skalweit hat uns kürzlich daran erinnert, daß die Reformatoren mit dem Begriff „Reformation“ als Selbstbezeichnung sehr zurückhaltend gewesen sind. „Reformation“ ist meines Erachtens ja ohnehin primär ein politischer Begriff. Wir wissen zwar alle, daß Politik und Religion im 16. Jahrhundert eine Einheit sind, aber das hindert uns nicht daran, immer wieder in moderne Kategorien zu verfallen, die eine Dissoziation der Lebensbereiche voraussetzen, was darauf hinausläuft, daß man wieder von zynischer Instrumentalisierung der Religion für politische Zwecke ausgeht. Im 16.Jahrhundert nur den Politiker Karl oder nur den Glaubenshelden zu sehen, ist sicherlich beides falsch, und ich glaube, man müßte noch eine Menge tun, um zu lernen, wie man seine politischen Interessen vertritt und gleichzeitig seinem religiösen Gewissen folgt. 
Außerdem hätte ich eine kleine Frage zu Karl V. Sie haben gesagt: „verfassungspolitisches Programm des Kaisers vom ersten Tag an“. Das kann ich nicht ganz einsehen. Vielleicht offenbare ich da nur meine Unkenntnis, aber ich bin gewohnt, Karl V. zu sehen als einen, der auf seine Rolle als Haupt des Reiches eigentlich von all seinen politischen Funktionen am schlechtesten vorbereitet war, und ich habe den Eindruck, daß er selbst auf dem Augsburger Reichstag 1530 von den Problemen des Reiches, ich will nicht gerade sagen keine Ahnung hatte, aber doch vergleichsweise nicht sehr gut informiert war. Man könnte die Frage auch anders stellen und einfach fragen, wer sind denn die Träger dieser Kontinuität, die zu Sigmund zurückreicht. Man weiß ja, daß in der Umgebung Karls, in seinem Behördenapparat, die Vertreter des Reiches nicht gerade die glänzendste Rolle gespielt haben. Die maßgebenden Funktionäre waren andere Leute. Meine Frage läuft also kurz gefaßt darauf hinaus: wo ist dieses verfassungspolitische Konzept vom ersten Tag an zu identifizieren?

Scblosser: Herr Angermeier, als Rechtshistoriker habe ich natürlich inmitten eines Kreises von Historikern eine sehr verkürzte Frage an Sie zu stellen. Wenn ich Sie richtig verstanden habe, dann haben Sie gesagt, der Urgrund der universalistischen Reichspolitik Karls V. sei sein mittelalterliches Selbstverständnis. Das ist insofern aus der Sicht des Rechtshistorikers eine hochinteressante wie aufregende Feststellung, wenn man sich ein Phänomen, ein geistiges Phänomen, vor Augen hält, und diesem gilt meine Frage: Würden Sie dieses geistige Phänomen auch mit berücksichtigen? Wir sind doch in einer Zeit, und ich darf bitten, mir die primär juristische Reflexionsebene nachzusehen, da sich im Bereich des juristischen Denkens doch eine säkulare Welt anbahnt, für die ich nur Stichworte geben möchte: Humanismus, Renaissance, Spātscholastik und Naturrecht. Die Folge ist mit Sicherheit, daß auf der Ebene der Doktrin eine Reichsstaatsrechtslehre schon aktiv geworden ist, deren Grundlagen zwar das römische, das gelehrte Recht ist, die mir aber irgendwie doch vorwärts zeigt. Die konkrete Frage also: Wieso wird eine universalistische Reichspolitik aus dem mittelalterlichen Selbstverständnis des Kaisertums betrieben, wo doch der geistige Horizont ganz offensichtlich bereits in die Ferne zeigt? Und etwas Letztes noch. Es wurde hier nach der Gesetzgebung des Reichstages gefragt und gesagt, die Gesetzgebung des Reichstages sei etwas Modernes. Richtig. Nur eine kleine Bemerkung: War denn die Gesetzgebung des Reichstags bezogen auf die Praxis wirklich so bedeutend? Abgesehen von den Münzordnungen, vielleicht; die haben tatsächlich unmittelbar durchgeschlagen.

Glaser: Ich bitte darum, noch einmal auf den Begriff Hybris bei Karl V. zurückzukommen. Denn ich finde, da besteht eine gewisse Spannung zwischen diesem ausführlich begründeten Begriff auf der einen Seite und den mittelalterlichen Traditionen, in die Karl V. hineingestellt wurde. Ich weiß nicht, ob man diese Tradition, wenn es mittelalterliche Traditionen sind, dann zurückführen kann bis ins 15.Jahrhundert, und wenn es aber ältere und unter Umständen sogar viel ältere Traditionen des Kaisertums sind, die Karl V. unter Umständen besser kannte als die konkreten Verhältnisse im Reich 1519, wo ist dann eigentlich die Hybris, da dies dann nur das Resultat einer viel älteren Tradition wäre? 
Angermeier: Herr Reinhard, Sie fragen mich, ob ich nicht die Ansätze der Verfassungspolitik bei Karl V. 1521 überschätze. Manchmal darf und muß der Historiker ja auch aus dem argumentieren, was nicht gesagt wird, und hier argumentiere ich vor allem mit der Selbstverständlichkeit, mit der Karl V. das Lehnswesen als Grundlage seiner Politik betrachtet hat und zwar bereits in der Wahlkapitulation, die dann 1521 auf dem Reichstag revidiert wird. In allen Verfassungsfragen läßt Karl V. mit sich reden, aber im Lehnrecht nicht. Im Gegenteil, das Lehnrecht weitet er aus. War es z.B. Reichsrecht und Brauch, bei großen Friedbrüchen zwar dem Friedbrecher das Reichslehen abzunehmen, aber es wieder auszugeben an dessen Erben, so findet man speziell in der späteren Zeit Karls V. immer wieder die Bestimmung, daß die Lehen dem Friedbrecher abgenommen werden, aber der Kaiser sie zur eigenen Verfügung einzieht. Wie schon Maximilian 1495 und 1500 beim ersten Reichsregiment seine lehnsherrlichen Rechte wieder sehr stark zum Ausdruck gebracht hat, so ist ihm Karl V. beim Regiment von 1521 darin durchaus nachgefolgt. In seiner lehnsrechtlichen Position hat Karl V. nie mit sich reden lassen. Und dem ist hinzuzufügen, daß im Bereich des Landrechts, auch in der Art und Weise, wie er 1521 den Reichslandfrieden modifiziert, ein weiteres Beispiel dafür vorliegt, daß die Verfassungspolitik bei Karl V. bisher zu Unrecht völlig unterschätzt wurde und von ihm von Anfang an verfolgt wird. Schließlich sollte man einen Blick darauf werfen, wie er sofort bei der ersten Reichskammergerichtsordnung $z$ war das Reichskammergericht akzeptiert, aber die Besetzung des Reichskammergerichts mit kaiserlichen Räten verdoppelt und später auch seine Ächtungsgewalt wieder betont. Also auch hier nimmt er ganz die Traditionen von Friedrich III. und Maximilian wieder auf, die bereits an ihrer Reichsgerichtsbarkeit nicht rühren ließen. Smend hat die Steigerungen in diesem Bereich aufgezeigt. In der Gerichtsbarkeit hat Karl V. eine ganz konstruktive und konzise Verfassungspolitik getrieben, und es ist sicherlich bis zum heutigen Tage viel zu wenig beachtet worden, daß er bezüglich der Art und Weise, wie er das Reich handhaben wollte, ganz klare Vorstellungen gehabt und auch eine ganz deutliche Politik geführt hat. Der Meinung, Karl V. habe keinen Sinn für Verfahrensfragen gehabt, kann man ein sehr eindrucksvolles Beispiel entgegensetzen, nämlich als Philipp von Hessen sich 1530, ohne sich beurlauben zu lassen, vom Reichstag entfernte. Man muß im Reichstagsprotokoll von Tetleben verfolgen, wie Karl V. das Weggehen Philipps von Hessen mit der höchsten Delikatesse behandelt, wie er ständig auf die Reichsstände Rücksicht nimmt und wie dieses Verfahren in höchster Verfassungskonformität erfolgt. Tatsächlich hat Karl V. den Reichstag wirklich gesteigert. Er hat sehr wohl gewußt, was ein Reichstag ist, und er hat ihn vortrefflich geführt.

Herr Schlosser, Ihre Frage ist sehr schwer zu beantworten. Wieso bezieht sich Karl $V$. auf eine mittelalterliche Kaisertradition und wieso gibt es trotzdem den Fortschritt in eine neue Staatstheorie? Hier hat ja Heinrich Lutz ganz wesentliche Schritte getan, um klar dieses Fortschreiten, das Einsteigen Karls V. in die Staatstheorie seiner Zeit verständlich zu machen. Wie weit dies angeregt war durch Gattinara, das ist umstritten oder bestreitbar. Ich würde aber doch meinen, daß hier bei Karl V. zwei Dinge nebeneinanderstanden, die sich nicht ausschließen und die auch nicht vermischt werden dürfen. Auf der einen Seite wollte Karl sehr wohl die ganze Traditionalität des mittel- 
alterlichen Kaisertums erhalten und auf der anderen Seite hat er sich den Möglichkeiten neuer Entwicklungen nicht verschlossen, wobei ich meine, dies hat nie so weit geführt, daß er seine mittelalterliche Stellung jemals in Frage gestellt hätte.

Herr Glaser, Hybris, warum Hybris eigentlich erst seit Sigmund? Es gibt die Papstwahlen von 1159 und 1164, wo der Kaiser in die Kirchenpolitik eingreift. Wir haben dies auch bei den Ottonen. Die Rechte und Möglichkeiten, welche der Kaiser bei der Papstwahl hat, sind ja nicht formuliert gewesen. Negativ sind sie im Papstwahldekret von 1059 fixiert. Die Kardinäle wählen den Papst, vom Kaiser ist nicht die Rede. Daß aber der Kaiser einen hohen politischen Einfluß hatte oder jedenfalls haben konnte, ist trotzdem auch in der folgenden Zeit wohl unbestreitbar gewesen bis in die Zeit Karls V. hinein. Worin liegt eigentlich die Hybris, die seit Sigmund eintritt? Wenn der Papst im hohen Mittelalter sich in die Kirchenfragen via Papstwahl einmischt, so ist das eine politische Angelegenheit gewesen. Wenn der Kaiser aber seit 1414, also seit dem Konstanzer Konzil, per Dekret in die Kirchenhoheit eingreift, wenn er in die Kirchenorganisation, in das Kardinalkolleg eingreift, wenn er die Liturgie āndern will, wenn er dann 1530 und 1548 schließlich und endlich die Glaubensdefinition vornimmt im $\S 57$ des Augsburger Reichsabschieds 1530 und später wieder im Interim, dann ist das eine ganz wesentliche qualitative Steigerung der kaiserlichen Machtansprüche über die Kirche. Es geht nicht nur um die Abgrenzung von der Kirche, sondern um das Hineinregieren in die Kirche und hier würde ich sagen, im Hineinregieren in die Kirche sieht man seit Sigmund, seit 1414, eine ganz neue, hybride kaiserliche Vorstellung von den Rechten, die der Kaiser in der Kirche beansprucht, und diese Sache ist bei Karl V. noch offenkundiger, aber in ihrer hybriden Form auch zu Bruch gegangen.

Glaser: Dann wäre vielleicht über die Vorbildlichkeit Karls d. Großen zu reden, aber das wollen wir jetzt nicht tun, das führt einfach sicher zu weit.

Kobler: Wenn wir schon so intensiv bei Karl V. sind, so muß der Deutlichkeit wegen gesagt werden, daß Karl V. gerade 1521 für uns schwer faßbar ist, und weil die Wahlkapitulation herangezogen wurde, so möchte ich auch anführen, daß die Ratgeber die Wahlkapitulation aushandeln, und wir wissen nicht, ob Karl V. darauf Einfluß hatte; ähnliches gilt vom Wormser Reichstag 1521, wo die Umgebung des Kaisers wesentlich besser faßbar ist als Karl selbst. Bis 1530 ändert sich diese Sachlage nur wenig, bedenkt man den Einfluß von Gattinara. Auch für die ersten Jahre Granvellas gilt dies, wie z. B. ein Aktenstück aus dem Jahre 1531 bestätigt, in dem die Abgrenzung der Regierungskompetenzen Karls und Ferdinands (als römischer König) geregelt wird und das übrigens auch die von Herrn Angermeier zu Recht betonte große Bedeutung des Lehnswesens im Reich unterstreicht, wenn Karl V. in Lehnssachen sich alle Rechte vorbehält.

Grundmann: Sie haben gerade die Frage angesprochen, ob Kaiser Sigismund auch in seiner Politik auf den Reformkonzilien an sich eine Autorität allgemein hatte, wie es manchmal hier anklang. Das müßte ich in Frage stellen im Hinblick auf die Kon- 
zils- und Reichsversammlungsgeschichte des frühen Mittelalters: Merowinger, Karolinger, Ottonen bis hin zu den Staufern konnten zugunsten der Geistlichen oder entgegen den Geistlichen Gesetze erlassen, die in das Reichsrecht aufgenommen worden sind. So sehe ich Kaiser Sigismund wie auch Karl V. als eine Art Schlußlicht in einer Tradition, die natürlich durch die Akzente Humanismus, Reformation, neue Staatsgedanken (die aus dem Italienischen kommen) eine andere Schlagseite erhält und in etwas hineinführt, was wir zwar noch als aus dem Mittelalter kommend registrieren können, aber doch anderswo hinführt. Ich möchte nur betonen, daß, wenn man diese Fragen ausklammert, wie Herr Angermeier es in seinen Arbeiten tut, man nicht darum herumkommt, die Wurzeln im Mittelalter zu sehen und in der Rolle der Kaiser auf den Konzilien. Das war meine Frage.

Angermeier: Die Frage der Wahlkapitulation ist ein ganz heikles Problem. Aber ich muß Ihnen gestehen, die Wahlkapitulation Karls V. von 1519 nehme ich als ein Verfassungsdokument nicht so ernst wie Hartung. Das ist ein politischer Vertrag gewesen. Karl V. hat hier sehr viel zugegeben, denn er wollte gewählt werden. Aber wenn Sie sich die Wahlkapitulation anschauen, so hat sie ja nicht nur Karl V. gebrochen, sondern auch die Kurfürsten haben das getan. Sie verpflichten doch den Kaiser, er soll die Kirche schützen, er soll sich für die Kirche und für den Papst einsetzen. Haben sich die Kurfürsten dann hernach an die Wahlkapitulation gehalten? Die Kurfürsten hatten auch, wenn man die Wahlkapitulation von 1519 genau anschaut, wohl keine klaren Vorstellungen vom Reichsrecht. Sie brauchen nur mal anschauen, wie sich das im Artikel 24 mit der Rückgabe der Reichsterritorien verhält, wie es sich mit den Reichssteuern verhält.

Die Sache mit der Rolle der Kaiser und ihrer Einwirkung auf die Konzilien des frühen Mittelalters ist natürlich ein Problem für sich. Ich möchte aber doch eine Unterscheidung hier herausstellen, und zwar habe ich ja so großen Wert darauf gelegt, daß der Kaiser seit der Absetzung Wenzels 1399 die Machtbasis des Königtums verloren hat und sich nun eigentlich freischwebend in eine Theorie hineinbegibt, mit der Karl V. dann schließlich und endlich Schiffbruch erleidet. Wenn Sie sagen, die Bedeutung der Kaiser und der Könige im hohen Mittelalter ist doch auch gegeben, so antworte ich, daß damals die Kaiser auch als Könige noch eine Position besaßen und die Merowinger, die Karolinger nicht als Kaiser, sondern schon als Könige eine kirchenpolitische Gewalt ausübten. Diese königliche Gewalt war gerade für die Kaiser nach Wenzel eigentlich preisgegeben. Die Könige haben nach Sigmund von ihrer Königsgewalt recht wenig Gebrauch gemacht, und das ist die ganz veränderte Situation, die im Hinblick auf die Konzilien als hybrid verstanden werden muß im Gegensatz zum Frühund Hochmittelalter.

Grundmann: Ich finde, Sie haben ganz recht, wenn Sie sagen, die reale Machtbasis war verloren, aber die Idee und der Anspruch, die bleiben bestehen und das haben manche mit mehr oder weniger Glück wieder aufgenommen. Sigismund hat doch etwas mehr Macht und Möglichkeiten gehabt, bei Karl V. geschieht es dann im luftleeren Raum. 